\title{
Espaço Geofísica: o Ensino de Geofísica desde o Fundamental I
}

Ailton Marcos Bassini, Parque de Ciência e Tecnologia (CienTec) / USP

Copyright 2016, SBGf - Sociedade Brasileira de Geofísica

Este texto foi preparado para a apresentação no VII Simpósio Brasileiro de Geofísica, Ouro Preto, 25 a 27 de outubro de 2016. Seu conteúdo foi revisado pelo Comitê Técnico do VII SimBGf, mas não necessariamente representa a opinião da SBGf ou de seus associados. E proibida a reprodução total ou parcial deste material para propósitos comerciais sem prévia autorização da SBGf.

\section{Resumo}

The Espaço Geofísica (EG) was created in 1999. This space of knowledge aims, mainly, to divulge Geophysics science, in class rooms at the Parque CienTec, at cultural events, science fairs, at schools, ultimately as the mobile science project, which, roughly, intends to bring science to where the student is. That is done via lectures, computer and projector, videos, specifics softwares, along with geophysics devices such as the Digital Seismograph; always with colorful images and animations, as seen in the "Petrol Prospection" \& "Continental Drift" videos. The EG also prepare teachers and improve the quality the Geophysics graduation course newcomers at the USP.

\section{Introdução}

O Espaço Geofísica (EG) foi criado em 1999 e hoje ocupa uma sala com 80 lugares no Parque CienTec / USP, onde alunos de qualquer idade, de forma interativa, podem conhecer melhor o Planeta Terra. Este espaço do conhecimento visa o ensino de geofísica, além da divulgação desta ciência ainda desconhecida. Com esses objetivos em mente, foi usada a estrutura construída no Parque CienTec, eventos culturais em geral, como feiras de ciência, USP \& Profissões e Semana C \& T, além de ir às escolas. Tudo foi viabilizado através de palestra, através de computador e Datashow, com o uso de equipamentos geofísicos, como o sismógrafo, eletroimã, etc., além de vídeos, programas de computador específicos, sempre com imagens coloridas e animações, como no caso da Prospecção de Petróleo ou da Deriva Continental. Além desses, foi editado um jornal e criada uma mala direta de divulgação.

O EG visa ainda melhorar a qualidade dos ingressantes ao curso de graduação de Geofísica na USP e evitar a evasão dos graduandos na área. Pode ainda preparar professores, além da divulgação das atividades do Parque CienTec, junto à comunidade. Um problema no início: a maioria dos alunos das escolas públicas não têm recursos para pagar um ônibus para vir ao CienTec. Levando o EG até as escolas, foi a melhor maneira que encontramos para contornar esse problema, com o projeto Ciência Móvel (CM), que grosso modo pretende levar ciência onde o aluno está.

A infraestrutura montada no Parque CienTec (sala, esculturas e corredor didático), foi aproveitada para sediar o Espaço Geofísica.

\section{Metodologia/ Problema Investigado}

Como adequar a linguagem, o conteúdo tão pesado a qualquer faixa etária? "Brincar" com os equipamentos geofísicos, imagens coloridas e filmes, pequenos vídeos feitos no próprio EG foram a solução encontrada. $\mathrm{Na}$ Figura 1, esculturas do interior da Terra e da Deriva Continental auxiliavam na avaliação da turma, sobre o que sabiam sobre Geofísica e introdução do passeio.

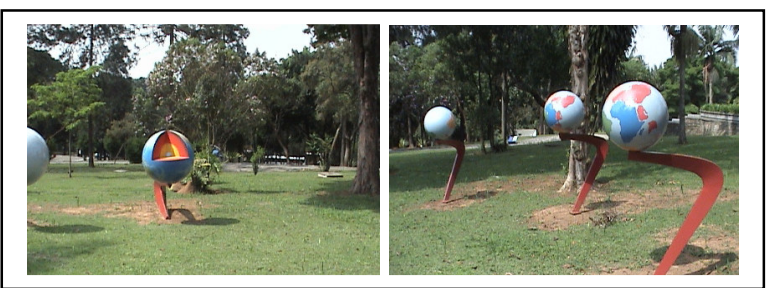

Figura 1 - Esculturas da Terra e da Deriva Continental.

Além disso, o antigo prédio da geofísica foi grafitado, simulando uma "Viagem ao centro da Terra", num corredor de $18,2 \mathrm{~m}$ em escala, mostrando diversos parâmetros geofísicos, como pressão, temperatura, densidade, velocidade das ondas $\mathrm{P}$ e $\mathrm{S}$, correspondendo aos $6.378 \mathrm{~km}$ do raio da Terra. Fotos do corredor didático são mostradas na Figura 2. Paralelamente, diversos equipamentos e diferentes apresentações para diferentes faixas etárias.

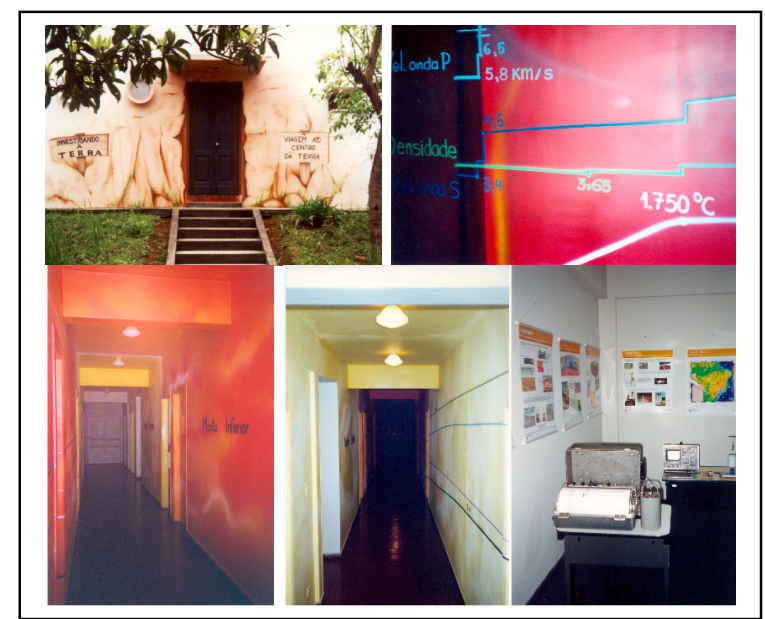

Figura 2: Corredor didático "Viagem ao Centro da Terra", com as camadas, parâmetros geofísicos e equipamentos.

Como aumentar o público? Via mala direta, dirigida principalmente às escolas, a confecção de um jornal, que tratava de diversos assuntos atuais, ligados à Geofísica, 
como foi o caso da Tsunami de 2004 na Sumatra ou da prospecção de petróleo, ambos na Figura 3.
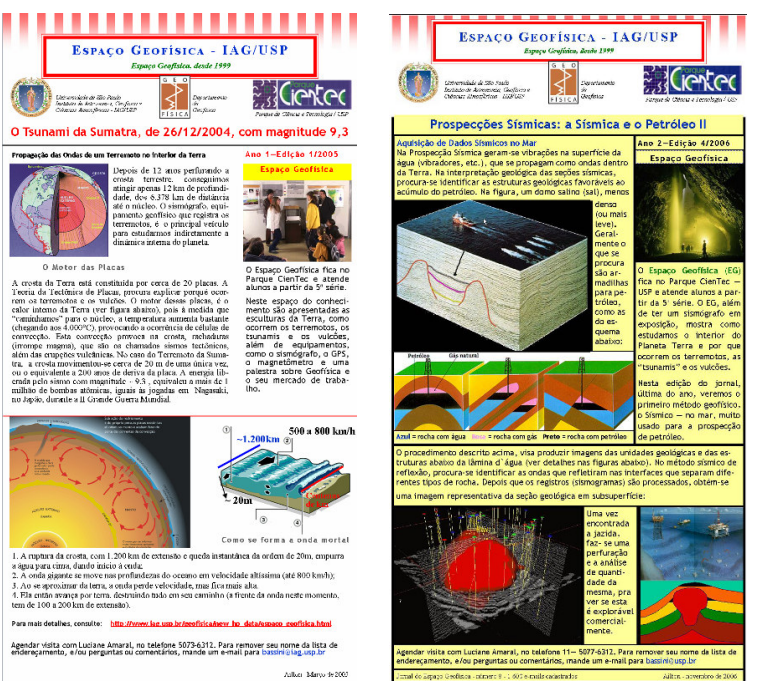

Figura 3 - O Jornal do Espaço Geofísica, $n^{\circ} 1$ e $n^{\circ} 8$.

Outra solução foi deixar disponível a professores e agentes multiplicadores (em escolas, 10 alunos eram treinados para apresentar Geofísica), todo o acervo do EG, incluindo aí os programas de computador, como o Seismic Waves e o da Deriva Continental e a Tectônica. Nas apresentações estilo show do EG, na Figura 4, total interatividade e privilegiar "brincadeiras" (o lúdico) com os equipamentos geofísicos, enquanto conceitos teóricos e outros eram inseridos na conversa. Palestras em outras cidades, só para professores, foi outro recurso utilizado. Cerca de 30 pôsteres temáticos foram confeccionados para ilustrar os ambientes internos e externos ao Parque.

Todo ano também, é escolhido um tema principal, como "Os Terremotos e o Campo Geomagnético", que conta uma história, um roteiro com 5 (cinco) equipamentos: o sismógrafo (provocar um terremoto e prospecção de petróleo), o Porquinho (lei de Snell e propagação de ondas sísmicas), a Pilha de Volta (campos e prospecção geoelétrica), o gerador de eletricidade (meio ambiente, dínamo, leis de Maxwel, mini-Itaipu e gerar o campo geomagnético) e finalmente o eletroímã, para explicar em conjunto com a magnetosfera (vídeo) como funciona e para que serve o campo geomagnético.

\section{Resultados}

A Figura 5 mostra o número de visitantes, pessoas atendidas no Espaço Geofísica em 16 anos, ano a ano. No total, 102.535 pessoas passaram por uma aula no EG. Só este número, bastante expressivo, já justificaria a existência do EG. Porém, aliado a isto, durante diversos anos, o EG foi o carro chefe do Parque, o mais procurado e visitado, tanto no Parque quanto no $\mathrm{CM}$. Os resultados com o corredor didático foram ótimos, porque no escuro o aluno tinha a sensação de entrar numa caverna e de "entrar Terra adentro", observando de um lado as profundidades e de outro os parâmetros geofísicos.
Professores e coordenadores, até hoje solicitam e comentam o quão didático foi o passeio por ele. Igual importância foi dada pelos avaliadores, para as 4 esculturas ao redor do EG. A mala direta e o jornal foram excelentes para divulgar, mas principalmente formar um público constante, as escolas. Levar o $E G$ até as escolas teve diversas vantagens: a primeira, aumentar bastante 0 público alvo, pois eram atendidos de 700 a 1.300 alunos por dia, com $\sim 8$ saídas do CM por mês, durante as aulas escolares. Os agentes multiplicadores foram a segunda vantagem: cada escola visitada para uma feira de ciências, ganhou $\sim 10$ alunos treinados para apresentar Geofísica.

A partir de 2009 na Bahia, essas apresentações feitas em escolas de São Paulo, foram levadas para o congresso da SBGf, numa parceria com outras universidades (UFPA, UnB, Unicamp). Pela primeira vez, alunos do Ensino Fundamental, Médio, Técnico e Faculdades de Salvador, Rio de Janeiro, Foz de Iguaçu (AGU), tiveram a oportunidade de entrar num congresso internacional e de conhecer a Geofísica e uma nova profissão.

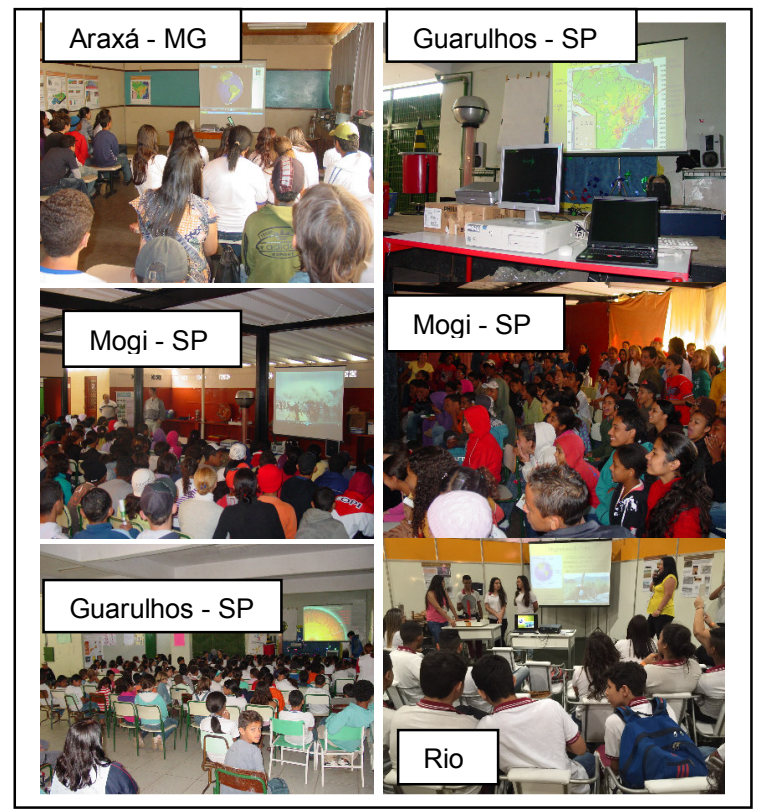

Figura 4 - Apresentações do Espaço Geofísica.

Alguns resultados que não aparecem nos gráficos: estagiários do Parque, de outras graduações, que não Geofísica, bem treinados em apresentar Geofísica nas escolas, feiras de ciência e congressos da SBGf. Estagiários do Parque e alunos de graduação em Geofísica, que passaram a entender melhor a Geofísica e a se interessarem mais pelo curso escolhido. Estagiários do Parque, de outras graduações, que mudaram de curso, após conhecerem o EG. Alunos de outras faculdades, que visitaram o EG, saíram da engenharia, por exemplo, e hoje são Geofísicos. Alunos de escolas distantes do Parque e que prestaram vestibular para Geofísica, após visita do CM. 
Um exemplo de resultado producente e executado fora de São Paulo: fazer uma mala direta para 2 ou 3 cidades próximas e com muitas escolas. Enviar um convite para apresentação da Geofísica na escola, a custo zero para a escola. Com 5 escolas inscritas, nos deslocamos para uma base numa das cidades e cerca de 4 mil pessoas fora de São Paulo foram apresentadas à Geofísica $(\sim 800 /$ dia). A ressaltar, na primeira escola no primeiro dia, durante as apresentações, recebemos 7 convites para atuar em outras escolas da região. Basicamente, esta metodologia é a que aplico nas cidades do congresso da SBGf, a cada 2 anos, limitados a 300 alunos/dia.

Como resultado positivo ainda a ressaltar, que até hoje há solicitações para o $\mathrm{CM}$, embora este tenha sido descontinuado no início de 2013, quando da mudança de direção.

Clientes antigos vêm ao Parque atualmente, somente para fazer Geofísica.

\section{Discussão e Conclusões}

A maioria dos visitantes, ao chegarem ao EG nesses 16 anos, não sabia o que era e para que servia a Geofísica. Por conta disso, um espaço dedicado a divulgar a ciência Geofísica, com qualquer conteúdo, é bem-vindo e tem sua importância.

Alunos do Ensino Fundamental I e II mostraram-se muito mais interessados em geofísica, nos temas abordados no EG, que alunos do Ensino Médio.

Incluir Geofísica num ciência móvel vale a pena investir novamente, porque atinge alunos de outras cidades, que sem o CM dificilmente veriam Geofísica na vida. Para tanto, alguns poucos estagiários bem treinados e um pequeno investimento para os deslocamentos seriam necessários e suficientes. O Espaço Geofísica nos eventos da SBGf tem sido executado com 4 pessoas (1 coordenador e 3 "estagiários").

$\mathrm{Na}$ Figura 5, o pico em 2008 deveu-se a dois fatos: assumi a coordenação do $\mathrm{CM}$ e o Agendamento do Parque, simultaneamente, inscrevendo a Geofísica em muitos eventos naquele ano. $\mathrm{Em}$ anos posteriores, a diminuição de visitantes deveu-se a vários fatos, como a gripe suína em 2009, falta de motoristas, redução no quadro de estagiários e posteriormente no final de 2012, com a mudança de direção no Parque e término do CM.

A reação e os resultados do EG com estagiários da graduação de diversas áreas, além de uma surpresa, mostram que espaços específicos podem ajudar na reformulação de uma decisão de uma profissão.

O Jornal do Espaço Geofísica, enviado às escolas foi uma maneira sutil de atingir professores das áreas de ciências, física e de geografia.

Com a divulgação e o conteúdo, EG foi a atração carrochefe do CienTec por muitos anos. Seu conteúdo sempre foi elogiado, não importando que tema ou que apresentação fosse escolhida para aquele ano. No caso do CM, solicitações em 2016, de algo que acabou em 2012, falam por si só. Comentário de uma professora de Química, após apresentação do EG: "se no meu tempo, eu tivesse visto uma apresentação assim, eu teria feito Geofísica, ao invés de Química".

As avaliações das escolas visitantes, por escrito, permitem dizer que vale a pena continuar.

\section{Agradecimentos}

Agradeço ao grupo de Geofísica do IAG/USP por colaborar com equipamentos e conteúdo, principalmente dos pôsteres temáticos. Em particular à Profa. Marta Mantovani por receber o EG no Parque e também por me atribuir a coordenação do Ciência Móvel durante sua gestão. Ao grupo de estagiários (as), que entenderam e se dedicaram ao CM, e em particular a Francine Aguiar, Luciana Sayuri e Melissa de Sousa, alunas/formadas em Ciências da Natureza/USP, e que até hoje, divulgam e apresentam EG/Geofísica nos congressos.

Agradeço à Profa. Ellen Gomes (UFPA), por viabilizar os atendimentos do EG nos congressos da SBGf, pela parceria sempre produtiva e por seu apoio irrestrito.

Finalmente, a professores e coordenadores de escolas, que solicitaram e ainda hoje solicitam o $\mathrm{CM}$ em suas escolas.

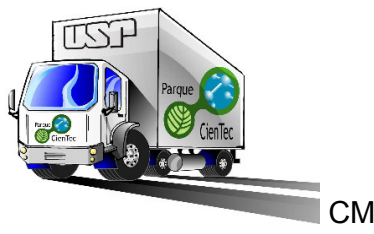

\section{Referências}

Assumpção, M., Barbosa, J., Berrocal, J., Bassini, A.M., Veloso, J., Marza, V.I., Huelsen, M.G., Ribotta, L. C., 1997. Seismicity Patterns and Focal Mechanisms in Southeastern Brazil. RBGf. vol. 15, n²: 119-132.

Bassini, A. M., et al (03 co-authors), 1984. Abalos Sísmicos Sentidos na Região Meridional do Brasil em 1982. Revista Brasileira de Geofísica. vol.2: 85-94.

Berrocal, J., Fernandes, C., Bueno, A., Seixas, N., Bassini, A.M., 1993. Seismic Activity in Monsuaba (State of Rio de Janeiro, between 1988 December and 1989 February. Geophysics Journal Int. vol. 113, 73-82.

Gennes, Pierre-Gilles de, 1997. Les Objets Fragiles. Editora da Unicamp. 


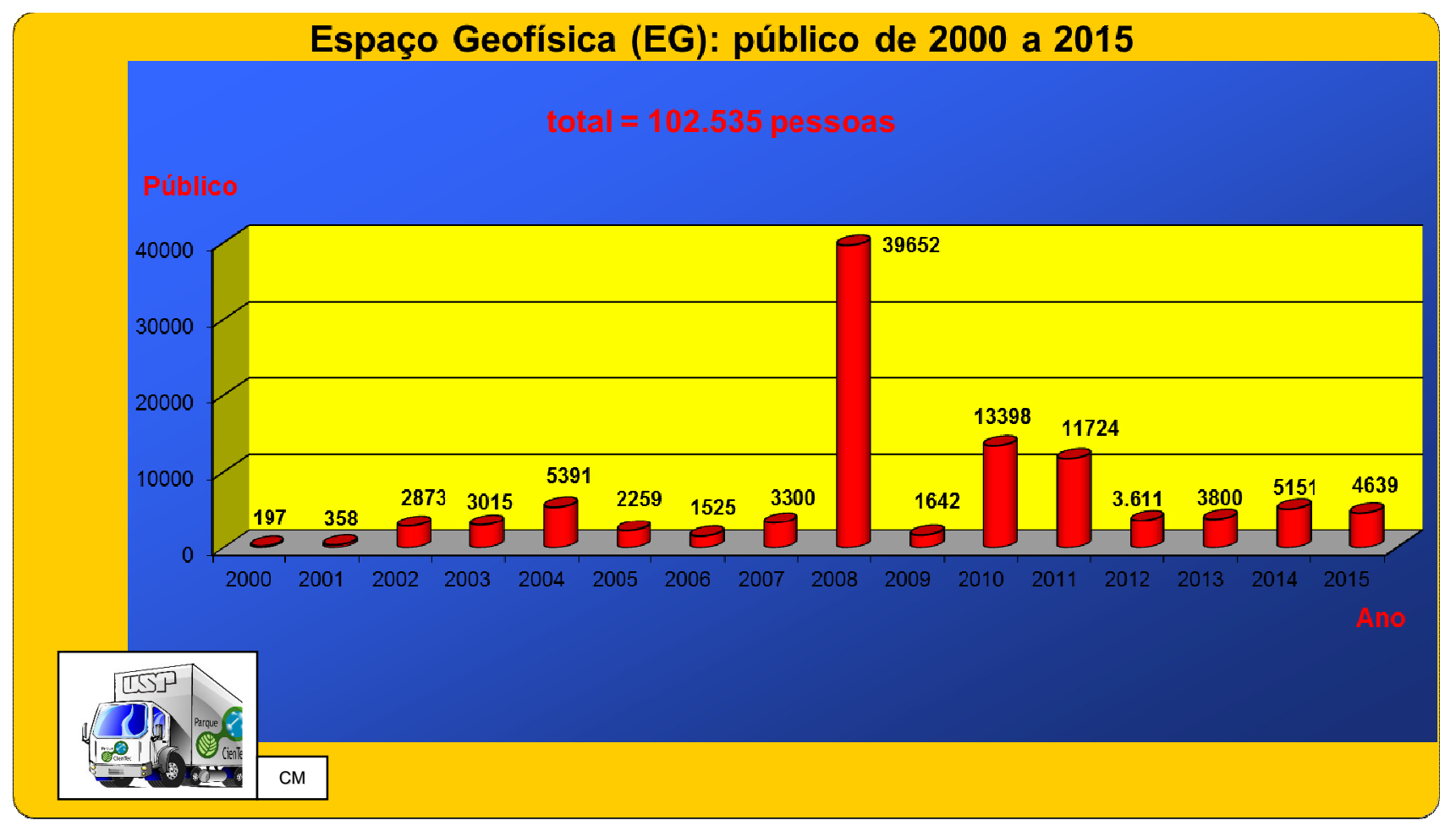

Figura 5 - Quantidade de visitantes no Espaço Geofísica. 